\title{
Virulence Factors in Bacillus thuringiensis: Purification and Properties of a Protein Inhibitor of Immunity in Insects
}

\author{
By I. SIDEN, G. DALHAMMAR, B. TELANDER, H. G. BOMAN \\ AND H. SOMERVILLE* \\ Department of Microbiology, University of Stockholm, \\ $S$-106 91 Stockholm, Sweden \\ * Shell Biosciences Laboratory, Sittingbourne Research Centre, \\ Sittingbourne, Kent ME9 8AG
}

(Received 27 November 1978)

\begin{abstract}
We have previously shown that Bacillus thuringiensis subsp. alesti, serotype 3, produces two extracellular inhibitors of the immune system of Saturniid pupae (designated inhibitors A and B; Edlund et al., 1976). Starting from the culture supernatant of a new mutant of $B$. thuringiensis with a decreased extracellular proteolytic activity, we have now purified immune inhibitor A (InA). The procedure described consists of three steps: ultrafiltration, precipitation with ammonium sulphate and chromatography on hydroxylapatite. Purified InA gave a single band on polyacrylamide gel electrophoresis using either a gel concentration of $7.5 \%(\mathrm{w} / \mathrm{v})$ and reducing and denaturing conditions or a gradient gel and native conditions. In both cases the apparent molecular weight was 78000 . A certain amount of proteolytic activity was always co-purified with InA but the two activities could be dissociated by heat or EDTA treatment. Antiserum against purified InA gave only one sharp precipitation band on immunodiffusion against InA with or without EDTA. InA inhibited the in vitro killing of Escherichia coli by immune haemolymph but did not affect the killing of Bacillus subtilis. InA was toxic for Drosophila when injected into the abdomen of adult male flies.
\end{abstract}

\section{INTRODUCTION}

Different strains and formulations of Bacillus thuringiensis have been used successfully as insecticides (Bulla et al., 1975). The organism is therefore fairly well characterized and it is generally accepted that most of the insecticidal properties are derived from the endotoxin (Faust, 1975) which is present both in a crystalline inclusion and in the spore coat (Delafield et al., 1968; Somerville \& Pockett, 1975).

Production of toxins is, however, only one of the factors which make up the overall pathogenicity of a bacterial strain. Other important variables are invasiveness and the ability to withstand the immune defences of the host. In an attempt to investigate the latter property, we found that $B$. thuringiensis produces two different substances which block separate parts of the immune system of Saturniid pupae (Edlund et al., 1976). One of these substances, immune inhibitor A (InA), was sensitive to heat and to trichloroacetic acid. As an in vitro assay for InA, we used its ability to block the lysis of Escherichia coli caused by immune haemolymph from pupae of Hyalophora cecropia. The second substance, immune inhibitor B (InB), was unaffected by heating to $90^{\circ} \mathrm{C}$ for $5 \mathrm{~min}$ and was not precipitated by trichloroacetic acid. As an in vitro assay for $\operatorname{InB}$, we used its ability to inhibit the killing of Bacillus cereus (Edlund et al., 1976).

Starting from a new mutant with decreased proteolytic activity, we have now purified InA by a three-step procedure. The purified material was homogeneous but it always 
contained a certain level of proteolytic activity. InA was found to be a single polypeptide chain with a molecular weight of 78000 . A preliminary characterization of the biological activity of InA is given.

\section{METHODS}

Bacteria. The parental strain of Bacillus thuringiensis, Bt7 (identical to strain HL2 of Somerville, 1971), is a crystal-negative mutant derived from a penicillin- and streptomycin-resistant line of $B$. thuringiensis subsp. alesti, serotype 3. Other bacteria used were Bacillus cereus Bc11, Bacillus subtilis Bs11 and Escherichia coli D31, all streptomycin-resistant, and Enterobacter cloacae $\beta 12$, a nalidixic acid-resistant mutant (Boman et al., 1974; Edlund et al., 1976).

Media. Cultures of 5 to $10 \mathrm{ml}$ of all bacteria were grown in LB medium; solid media were LA plates (Bertani, 1951) supplemented with either streptomycin $\left(100 \mu \mathrm{g} \mathrm{ml}^{-1}\right)$ or nalidixic acid $\left(25 \mu \mathrm{g} \mathrm{ml}^{-1}\right)$. For large-scale liquid cultures of $B$. thuringiensis, the medium contained $13 \mathrm{~g}$ nutrient broth (Oxoid) $\mathrm{l}^{-1}$ supplemented with $1 \mathrm{mM}-\mathrm{MgCl}_{2}, 0.5 \mathrm{~mm}-\mathrm{MnCl}_{2}$ and $7 \mathrm{mM}-\mathrm{CaCl}_{2}$. Mutants of $\mathrm{Bt} 7$ deficient in proteolytic enzymes were selected on nutrient agar (Oxoid) plates supplemented with $15 \%$ (w/v) skim-milk (Brown \& Scott Foster, 1970).

Isolation of mutants. Washed cells of $\mathrm{Bt} 7$ (about $2 \times 10^{7} \mathrm{ml}^{-1}$ ) were incubated at $37^{\circ} \mathrm{C}$ for $15 \mathrm{~min}$ in $0.1 \mathrm{M}-$ citrate buffer, pH 5.5, containing $N$-methyl- $N^{\prime}$-nitro- $N$-nitrosoguanidine $\left(200 \mu \mathrm{g} \mathrm{ml}^{-1}\right.$; Aldrich Chemical Co., Milwaukee, Wis., U.S.A.). After washing twice with $0 \cdot 1 \mathrm{M}-\mathrm{K}_{2} \mathrm{HPO}_{4} / \mathrm{KH}_{2} \mathrm{PO}_{4}$ buffer, pH 7.0, $0 \cdot 1 \mathrm{ml}$ bacterial suspension was added to $5 \mathrm{ml} \mathrm{LB}$ medium and allowed to grow overnight at $37^{\circ} \mathrm{C}$. Appropriate dilutions were then spread on skim-milk plates and incubated overnight. Normal colonies produced clearing zones of a few millimetres diameter, but 2 out of about 6000 had no detectable clearing zones. One of these, designated Bt75, was selected for further work. Growth in sporulation medium revealed that Bt75 did not form spores; under the same conditions the parental strain Bt7 sporulated normally.

Preparation of sterile culture filtrate. Starting material for the purification of InA was obtained from eight cultures grown in Fernbach flasks, each containing 21 medium. The flasks were inoculated with $80 \mathrm{ml}$ of an overnight culture of Bt75 grown in the same medium. After $22 \mathrm{~h}$ incubation on a rotary shaker at $30^{\circ} \mathrm{C}$, the bacteria were sedimented by centrifugation at room temperature. The supernatant was sterilized by filtration through a membrane filter $(0.45 \mu \mathrm{m}$ pore size).

Insects and their immunization. Immune haemolymph was prepared from diapausing pupae of Hyalophora cecropia (Faye et al., 1975). In vivo experiments were performed with pupae of Callosamia promethea, as described by Edlund et al. (1976). Male Drosophila melanogaster, strain KAS 60, were used for toxicity tests.

Assay for InA. The antibacterial activity present in immune haemolymph was assayed with $E$. coli D31 or B. subtilis Bs11 (Boman et al., 1974). The specific ability of InA to prevent the lysis of $E$. coli was used for its assay (Edlund $e t$ al., 1976). Equal volumes $(25 \mu \mathrm{l})$ of sample and haemolymph from $\mathrm{H}$. cecropia were incubated at $37^{\circ} \mathrm{C}$ for $30 \mathrm{~min}$. After this time, $25 \mu \mathrm{l}$ was withdrawn and added to $1 \mathrm{ml} 0 \cdot 1 \mathrm{M}-\mathrm{K}_{2} \mathrm{HPO}_{4} /$ $\mathrm{KH}_{2} \mathrm{PO}_{4}$ buffer, pH 6.4, containing 2 mM-dithiothreitol and about $4 \times 10^{7}$ viable cells of $E$. coli $\mathrm{D} 31$. Bacterial lysis was measured at room temperature in a Zeiss PMQ III spectrophotometer as the decrease in absorbance at $450 \mathrm{~nm}$ during $2 \mathrm{~min}$. All dilutions and controls were performed with $\mathrm{K}_{2} \mathrm{HPO}_{4} / \mathrm{KH}_{2} \mathrm{PO}_{4}$ buffer containing bovine serum albumin $\left(1\right.$ or $\left.10 \mathrm{mg} \mathrm{ml}^{-1}\right)$. The total number of units in a sample was calculated by multiplying the relative inhibition by the dilution factor (e.g. a sample diluted ninefold and giving $35 \%$ inhibition contained $0.35 \times 9=3.15$ units).

Assay of proteolytic activity. The procedure used was a slight modification of the original method of Kunitz (1946). The substrate was $1 \%$ (w/v) casein, dissolved in $0 \cdot 1 \mathrm{M}-\mathrm{K}_{2} \mathrm{HPO}_{4} / \mathrm{KH}_{2} \mathrm{PO}_{4}$ buffer, pH $6 \cdot 4$, and denatured by heating at $100{ }^{\circ} \mathrm{C}$ for $15 \mathrm{~min}$. Equal volumes $(0.4 \mathrm{ml})$ of substrate and sample were incubated at $37^{\circ} \mathrm{C}$ for $20 \mathrm{~min}$. The reaction was terminated by the addition of $1 \mathrm{ml}$ trichloroacetic acid $(6 \%$, w/v). The precipitate obtained was removed by centrifugation and the supernatant was filtered through a membrane filter $(0.45 \mu \mathrm{m}$ pore size). The absorbance of the clear supernatant was measured at $280 \mathrm{~nm}$ against a blank to which trichloroacetic acid was added before the sample. A sample absorbance of 1.00 was defined as one unit of proteolytic activity.

Assay for protein. In chromatographic fractions, the amount of protein was monitored as the absorbance at $280 \mathrm{~nm}$; for other samples, Lowry's method was used.

Analytical electrophoresis. Polyacrylamide gel electrophoresis was performed essentially according to Maizel (1969) using 7.5\% (w/v) gels and Pharmacia apparatus GE-4. Gels were stained with $0.25 \%$ Coomassie brilliant blue according to Weber \& Osborn (1969). Gradient gel electrophoresis was performed in borate buffer, $\mathrm{pH} 8 \cdot 35$, with PAA 4/30 gels from Pharmacia. Experimental details were as recommended by the manufacturer.

Materials. Hydroxylapatite (Bio-Gel HT) for chromatography was from Bio-Rad Laboratories; reference proteins used for determination of molecular weight were the highest grades available from Sigma. 


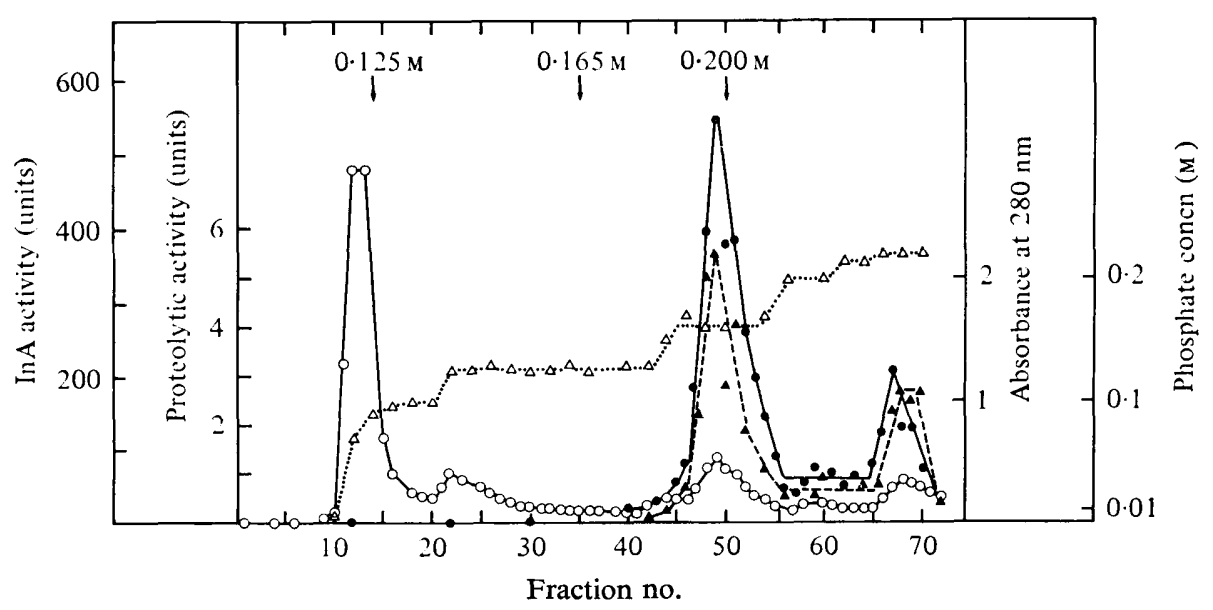

Fig. 1. Chromatographic purification of InA on a column $(15 \times 1.4 \mathrm{~cm})$ of hydroxylapatite equilibrated with $0.001 \mathrm{M}-\mathrm{K}_{2} \mathrm{HPO}_{4} / \mathrm{KH}_{2} \mathrm{PO}_{4}$ buffer, $\mathrm{pH} 6.4$, at the start. Elution was first performed with $0.1 \mathrm{M}$ buffer and then the concentration was increased stepwise as indicated by the arrows. The fractions collected were assayed for salt concentration by conductivity $(\triangle)$, ultraviolet absorbance at $280 \mathrm{~nm}(\mathrm{O})$, InA activity $(\boldsymbol{O})$ and proteolytic activity $(\boldsymbol{\Delta})$.

\section{RESULTS}

Purification of immune inhibitor $A$ (InA)

Sterile culture filtrate from strain $\mathrm{Bt} 75$ was used as the starting material for the purification of InA. A typical preparation starting from 161 of sterile culture filtrate was performed at about $4{ }^{\circ} \mathrm{C}$ as follows.

Step 1. The filtrate was concentrated about 100-fold in an Amicon 202 ultrafiltration cell with filter PM10; this required about 12 to $14 \mathrm{~d}$ with one or two daily changes of filter. The solution was then equilibrated with $0.05 \mathrm{M}-\mathrm{K}_{2} \mathrm{HPO}_{4} / \mathrm{KH}_{2} \mathrm{PO}_{4}$ buffer, $\mathrm{pH} 6.4$, and simultaneously concentrated a further 10 -fold. The material so obtained had a total volume of $15 \mathrm{ml}$ and contained about 15000 units InA and $270 \mathrm{mg}$ protein.

Step 2. To $15 \mathrm{ml}$ of concentrated and dialysed extract was added $3.0 \mathrm{~g}$ solid ammonium sulphate to give $35 \%$ saturation at $4{ }^{\circ} \mathrm{C}$. After stirring for 5 to $10 \mathrm{~min}$, the solution was centrifuged at $20000 \mathrm{~g}$ for $15 \mathrm{~min}$ and the precipitate was discarded. The supernatant (total volume $17.2 \mathrm{ml}$ ) was brought to $60 \%$ saturation by adding another $2.6 \mathrm{~g}$ solid ammonium sulphate. The precipitate, which contained InA, was collected by centrifugation. It was dissolved in $5 \mathrm{ml} \mathrm{K} \mathrm{HPO}_{4} / \mathrm{KH}_{2} \mathrm{PO}_{4}$ buffer and contained about 8400 units InA and $123 \mathrm{mg}$ protein. The supernatant, which contained InB, was saved for further purification of this substance. After the assays, the InA solution was ultradialysed with 5 vol. $0.001 \mathrm{M}-\mathrm{K}_{2} \mathrm{HPO}_{4} /$ $\mathrm{KH}_{2} \mathrm{PO}_{4}$ buffer, $\mathrm{pH} 6 \cdot 4$.

Step 3. Dialysed material containing about 4000 units InA was applied to a column of hydroxylapatite $(15 \times 1.4 \mathrm{~cm})$. Elution was carried out stepwise using the following con-

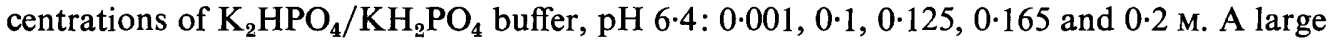
peak of inactive protein was eluted with $0.1 \mathrm{M}$ buffer, while the InA peak was eluted with $0 \cdot 165 \mathrm{M}$ buffer (Fig. 1). The column was regenerated by washing with $0.5 \mathrm{M}$ buffer and then re-equilibrated with $0.001 \mathrm{~m}$ buffer for the next experiment. The active material in the second peak (about 1800 units InA and $8 \mathrm{mg}$ protein in $9 \mathrm{ml}$ ) was pooled, concentrated about sixfold and used for further experiments. The progress of purification and the purity of the material obtained is illustrated in Fig. 2. Only one main band was obtained on polyacrylamide gel electrophoresis with purified InA. 


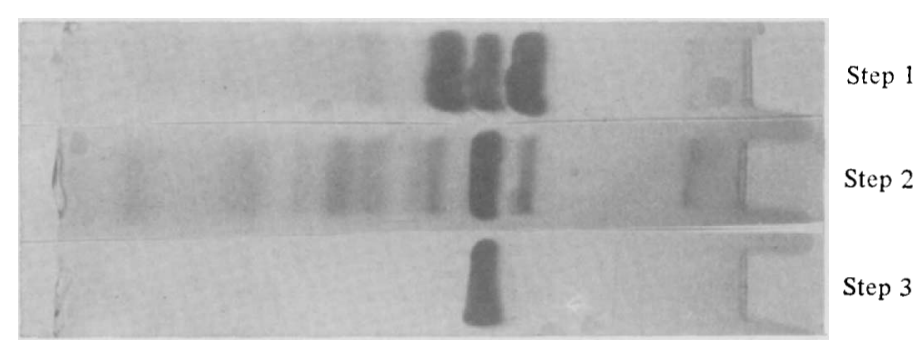

Fig. 2. Polyacrylamide gel electrophoresis of samples taken at each step during the purification of InA (see Resuits).

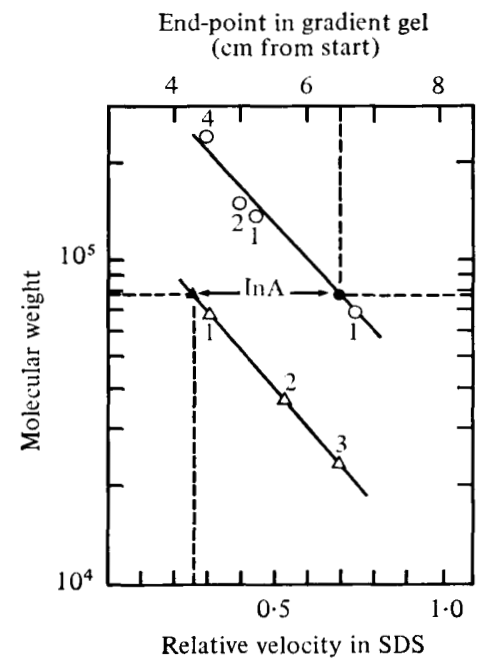

Fig. 3

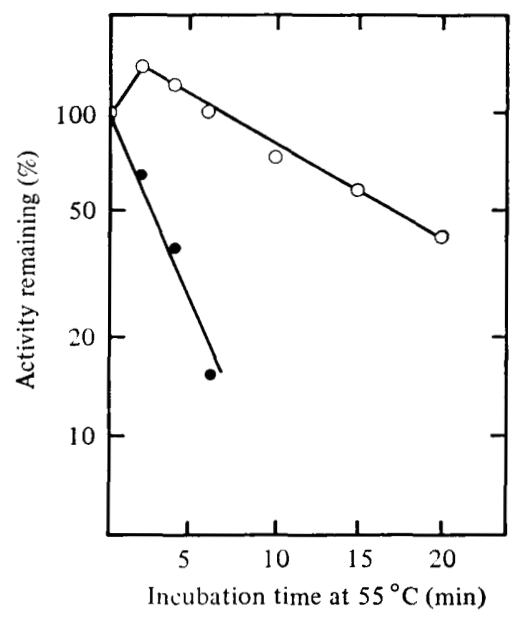

Fig. 4

Fig. 3. Determination of the molecular weight and sub-unit structure of purified InA: $\bigcirc$, $\bigcirc$, endpoint mobility after electrophoresis in polyacrylamide gradient gel (4 to $30 \%, \mathrm{w} / \mathrm{v})$ and borate buffer, pH $8.35 ; \Delta, \Delta$, relative migration velocity during electrophoresis in a $7.5 \%(\mathrm{w} / \mathrm{v})$ gel and SDS-containing buffer after reduction. The reference proteins used were: 1 , bovine serum albumin; 2 , yeast alcohol dehydrogenase; 3 , trypsin; 4 , catalase.

Fig. 4. Heat denaturation of InA at $55^{\circ} \mathrm{C}$. Samples were withdrawn at different times and assayed for InA activity (O) and proteolytic activity $(O)$.

\section{Properties of InA}

The molecular weight of purified InA determined by gel electrophoresis under both native and denaturing conditions [borate buffer, $\mathrm{pH} 8 \cdot 35$, and sodium dodecyl sulphate (SDS) after reduction, respectively] was 78000 in both cases (Fig. 3).

Despite the fact that our starting material was obtained from a mutant deficient in proteolytic enzymes, there was always a low level of proteolytic activity associated with InA. Since $\mathrm{Li} \&$ Yousten (1975) described a metalloprotease from B. thuringiensis, we investigated whether the InA activity and the proteolytic activity could be due to the same protein molecule. A heat denaturation experiment, in which samples were removed at different times and assayed for both lysis inhibition and proteolytic activity, showed that the two activities had different stabilities (Fig. 4). At $55^{\circ} \mathrm{C}$ the half-lives were $2 \mathrm{~min}$ for In A and $17 \mathrm{~min}$ for the proteolytic activity, respectively.

In other experiments, addition of 1 mM-EDTA to a purified sample of InA decreased the lysis inhibition to about $60 \%$ but totally removed the proteolytic activity. We tried to 


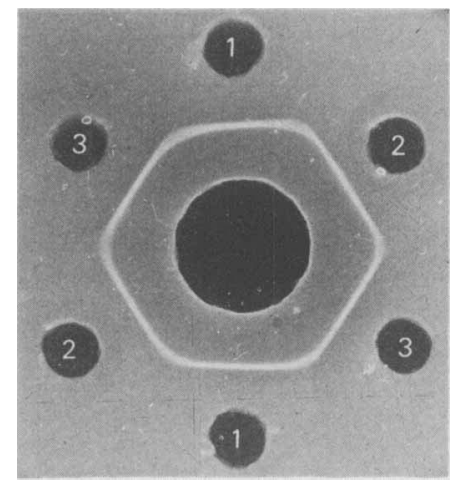

Fig. 5. Immunodiffusion experiment with purified InA and samples treated with different concentrations of EDTA. The centre well contained antiserum prepared against purified InA. Other wells contained: 1, InA; 2, InA plus 1 mM-EDTA; 3, InA plus 10 mM-EDTA.

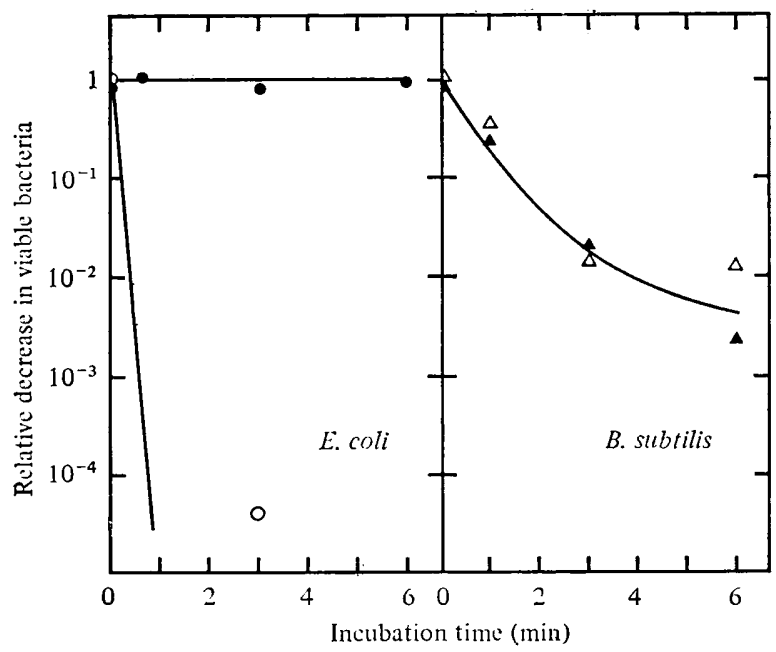

Fig. 6. Effect of InA on the killing of $E$. coli D31 and B. subtilis Bs11 by immune haemolymph from $H$. cecropia pupae: $\triangle, 100$ units InA; $\bigcirc, \triangle$, no InA (control).

regain both activities by adding $\mathrm{Co}^{2+}, \mathrm{Mn}^{2+}, \mathrm{Mg}^{2+}$ and $\mathrm{Zn}^{2+}$ (each at $2 \mathrm{~mm}$ ), but in no case was there a significant stimulation. The immunodiffusion pattern (Fig. 5) showed the same single sharp precipitation band with or without EDTA, thus providing no evidence for heterogeneity.

\section{Biological activity of InA}

Using immune haemolymph from $H$. cecropia we have previously shown that lipopolysaccharide from $E$. coli $\mathrm{K} 12$ inhibited the lethal activity against $E$. coli without affecting the killing of B. subtilis (Boman et al., 1974). We therefore investigated whether InA showed similar effects with the same two bacteria; InA did block the killing of $E$. coli but had no effect on the killing of B. subtilis (Fig. 6). We also investigated the ability of InA to affect the killing of $B$. cereus; in this case only a slight activity was found for a sample which was highly active in blocking the killing of $E$. coli.

One would predict that InA injected into pupae together with $E$. coli should give rise to a fatal infection. However, such experiments with pupae of $C$. promethea gave inconsistent results and implied that InA alone was toxic. We therefore performed toxicity tests by injecting different amounts of In A into adult Drosophila flies and recording survival times 


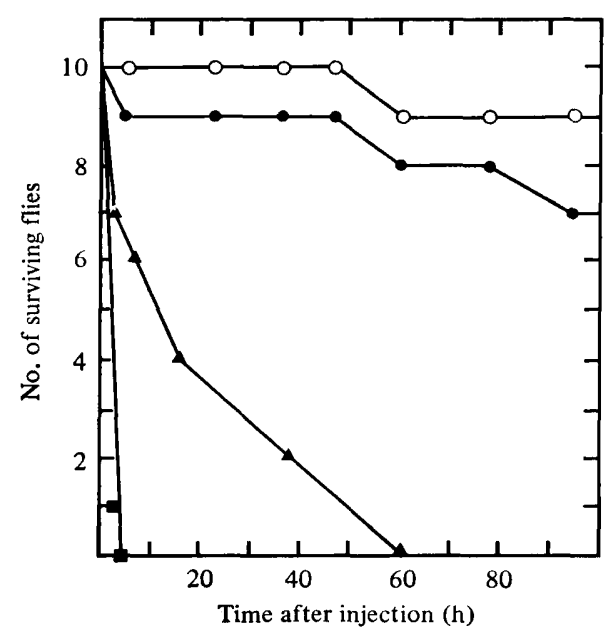

Fig. 7. Toxicity test of purified InA in Drosophila. Samples (about $0.25 \mu \mathrm{l}$ ) containing different amounts of InA were injected into the abdomen of male adult flies. For each treatment, 10 flies were injected and the number surviving was recorded at intervals after injection. Samples contained:

$0,5 \mathrm{ng}$ InA; $\Delta, 40 \mathrm{ng} \operatorname{InA} ; \boldsymbol{\square}, 200 \mathrm{ng}$ InA with or without EDTA; $O$, no InA (control).

(Fig. 7). An injection of $200 \mathrm{ng}$ InA (in $0.25 \mu \mathrm{l}$ ) was lethal within $4 \mathrm{~h}$. Pretreatment of InA with 1 mm-EDTA did not affect this toxicity; EDTA alone had no toxic effect. A dose of $40 \mathrm{ng}$ per fly was clearly toxic but $5 \mathrm{ng}$ gave an uncertain result.

\section{DISCUSSION}

The isolation of strain $\mathrm{Bt} 75$, a mutant with decreased proteolytic activity, was a necessary requirement for the purification described here. When we used the parental strain, Bt7, as starting material only a minor fraction of the biological activity was obtained and no bands could be seen on analytical polyacrylamide gel electrophoresis.

The three-step procedure used gave a product which was homogeneous in SDS-polyacrylamide gel electrophoresis (Fig. 2) and in immunodiffusion (Fig. 5). The overall recovery of InA was around $10 \%$ but it must be emphasized that this figure gives only the order of magnitude because the lysis inhibition assay can give values which vary by a factor of 2 . As an alternative to the first part of step 1, which was rather slow, we found that freeze-drying of the culture supernatant was satisfactory.

The apparent molecular weight of InA was the same under both native and denaturing and reducing conditions (Fig. 3), indicating that it is composed of a single polypeptide chain. There was always a close association between InA and a certain amount of proteolytic activity. However, since the protease-deficient mutant Bt75 showed a moderate decrease in InA activity and a large decrease in proteolytic activity compared with its parental strain Bt7, the major part of the proteolytic activity in the parental strain $\mathrm{Bt} 7$ was not part of the InA activity. With purified InA from Bt75, both EDTA treatment and heat denaturation (Fig. 4) could dissociate the remaining proteolytic activity from the inhibitory effect. It is therefore unlikely that the InA activity and the proteolytic activity could be the result of a single active site of an enzyme-like molecule. However, at present we cannot distinguish between the following three possibilities: (i) the proteolytic activity could be due to contamination of InA with a trace amount of a proteolytic enzyme like the metalloprotease described by Li \& Yousten (1975); (ii) the InA function and the proteolytic activity could be due to two different active sites on a single large polypeptide chain; (iii) the effects recorded with EDTA and heating could be due to alterations in the specificity of a single active site responsible for both the InA effect and the proteolytic activity. 
We have recently shown that the immune system in pupae of $H$. cecropia can be selectively inhibited with respect to one bacterium and unaffected with respect to others (Rasmuson \& Boman, 1977). As test organisms we used E. coli, B. subtilis and B. cereus. We have shown here that InA affected the killing of $E$. coli while having no influence on the killing of $B$. subtilis (Fig. 6). There was only a small effect on the killing of $B$. cereus and this was interpreted as being due to contamination with InB. It therefore appears that InA selectively blocks that part of the immune system responsible for the killing and lysis of $E$. coli. Immune haemolymph contains nine polypeptides (designated P1 to P9) which are synthesized as a specific response to infections (Faye et al., 1975; T. Rasmuson et al., unpublished results). Preliminary experiments indicate that InA affects P9A and P9B, two rather small proteins with bacteriolytic activities against $E$. coli. However, the nature of these protein-protein interactions is not clear and will be the subject of a future investigation.

Earlier experiments with $B$. thuringiensis mutants deficient in different toxins (Edlund et al., 1976) strongly suggested that InA cannot be identical to the $\delta$-endotoxin (Faust, 1975) or to the haemolytic factors of Pendelton et al. (1973). The experiments with EDTA and the molecular weight data (Fig. 3) exclude the possibility that InA could be identical to the metalloprotease of Li \& Yousten (1975). Since purified InA was toxic in Drosophila (Fig. 7), we conclude that InA must be a new toxin produced by $B$. thuringiensis.

There is no obvious biological reason why $B$. thuringiensis should produce a substance that would protect $E$. coli but not $B$. subtilis from the immune reactions of an insect. It is therefore possible that the targets of InA (proteins P9A and P9B) have a function other than the killing of $E$. coli or that InA has another target not yet found. The fact that InA was toxic suggests that the second alternative may be correct. Visual inspection of Drosophila injected with a lethal dose of InA indicated that the preparation produced muscular contractions and paralysis before the death of the flies. Further studies are therefore needed to clarify the molecular basis for the activities of InA.

This work was supported by the Swedish Natural Science Research Council (contracts B 2453-030 and B 2453-100) and the Knut and Alice Wallenberg Foundation. We thank James Ellerson for a critical reading of the manuscript.

\section{REFERENCES}

Bertani, G. (1951). Studies on lysogenesis. I. The mode of phage liberation by lysogenic Escherichia coli. Journal of Bacteriology 62, 293-300.

Boman, H. G., Nilsson-Faye, I., Paul, K. \& Rasmuson, T. (1974). Insect immunity. I. Characteristics of an inducible cell-free antibacterial reaction in hemolymph of Samia cynthia pupae. Infection and Immunity 10, 136-145.

Brown, M. R. W. \& ScotT Foster, J. H. (1970). A simple diagnostic milk medium for Pseudomonas aeruginosa. Journal of Clinical Pathology 23, 172-177.

Bulla, L. A., Rhodes, R. A. \& St Julian, G. (1975). Bacteria as insect pathogens. Annual Review of Microbiology 29, 163-190.

Delafield, F. P., Somerville, H. J. \& Rittenberg, S. C. (1968). Immunological homology between crystal and spore protein of Bacillus thuringiensis. Journal of Bacteriology 96, 713-720.

Edlưnd, T., Sidén, I. \& Boman, H. G. (1976). Evidence for two immune inhibitors from Bacillus thuringiensis interfering with the humoral defense system of Saturniid pupae. Infection and Immunity 14, 934-941.
FAUST, R. M. (1975). Toxins of Bacillus thuringiensis: mode of action. In Biological Regulation of Vectors, pp. 31-48. Edited by J. D. Briggs. Washington, D.C.: U.S. Department of Health, Education and Welfare.

Faye, I., Pye, A., Rasmuson, T., Boman, H. G. \& Boman, I. A. (1975). Insect immunity. II. Simultaneous induction of antibacterial activity and and selective synthesis of some hemolymph proteins in diapausing pupae of Hyalophora cecropia and Samia cynthia. Infection and Immunity 12, 1426-1438.

KunITZ, M. (1946). Crystalline soybean trypsin inhibitor. II. General properties. Journal of General Physiology 30, 291-310.

LI, E. \& Yousten, A. A. (1975). Metalloprotease from Bacillus thuringiensis. Applied Microbiology 30, 354-361.

MaIzel, J. V. (1969). Acrylamide gel electrophoresis of proteins and nucleic acids. In Fundamental Techniques in Virology, pp. 334-362. Edited by K. Habel \& N. P. Salzman. New York: Academic Press.

Pendelton, I. R., Bernheimer, A. W. \& Grushoff, 
P. (1973). Purification and partial characterization of hemolysins from Bacillus thuringiensis. Journal of Invertebrate Pathology 21, 131-135.

Rasmuson, T. \& Boman, H. G. (1977). The assay and the specificity problem in insect immunity. In Developmental Immunobiology, pp. 83-90. Edited by J. B. Solomon \& J. D. Horton. Amsterdam: Elsevier/North Holland.

SOMERVILle, H. J. (1971). Formation of the parasporal inclusion of Bacillus thuringiensis. European Journal of Biochemistry 18, 226-237.
Somerville, H. J. \& Pockett, H. V. (1975). An insect toxin from spores of Bacillus thuringiensis and Bacillus cereus. Journal of General Microbiology 87, 359-369.

WEBER, K. \& OSBORN, M. (1969). The reliability of molecular weight determinations by dodecyl sulfate-polyacrylamide gel electrophoresis. Journal of Biological Chemistry 244, 4406-4412. 